\title{
Is the Success of Plant Invasions the Result of Rapid Adaptive Evolution in Seed Traits? Evidence from a Latitudinal Rainfall Gradient
}

\author{
Marco A. Molina-Montenegro ${ }^{1,2,3 *}$, lan S. Acuña-Rodríguez ${ }^{1}$, Tomás S. M. Flores², \\ Rasme Hereme ${ }^{1}$, Alejandra Lafon ${ }^{4}$, Cristian Atala ${ }^{5}$ and Cristian Torres-Díaz ${ }^{6}$
}

${ }^{1}$ Centro de Estudios Avanzados en Ecología Molecular y Funcional, Instituto de Ciencias Biológicas, Universidad de Talca, Talca, Chile, ${ }^{2}$ Centro de Estudios Avanzados en Zonas Áridas, Facultad de Ciencias del Mar, Universidad Católica del Norte, Coquimbo, Chile, ${ }^{3}$ Research Program "Adaptation of the Agriculture to Climate Change" PIEl A2C2, Universidad de Talca, Talca, Chile, ${ }^{4}$ Centro de Investigación en Ecosistemas de la Patagonia, Coyhaique, Chile, ${ }^{5}$ Laboratorio de Anatomía y Ecología Funcional de Plantas, Instituto de Biología, Facultad de Ciencias, Pontificia Universidad Católica de Valparaíso, Valparaíso, Chile, ${ }^{6}$ Grupo de Biodiversidad y Cambio Global, Departamento de Ciencias Básicas, Universidad del Bío-Bío, Chillan, Chile

OPEN ACCESS

Edited by:

Naoki Osada,

Hokkaido University, Japan

Reviewed by:

Yan Sun,

Universität Tübingen, Germany Luis R. Pertierra

Universidad Rey Juan Carlos, Spain

*Correspondence:

Marco A. Molina-Montenegro marco.molina@utalca.cl

Specialty section:

This article was submitted to Evolutionary and Population Genetics, a section of the journal Frontiers in Plant Science

Received: 16 May 2017 Accepted: 05 February 2018 Published: 27 February 2018

Citation:

Molina-Montenegro MA, Acuña-Rodríguez IS, Flores TSM, Hereme R, Lafon A, Atala C and

Torres-Díaz C (2018) Is the Success of Plant Invasions the Result of Rapid Adaptive Evolution in Seed Traits? Evidence from a Latitudinal Rainfall Gradient. Front. Plant Sci. 9:208. doi: 10.3389/fp/s.2018.00208
It has been widely suggested that invasion success along broad environmental gradients may be partially due to phenotypic plasticity, but rapid evolution could also be a relevant factor for invasions. Seed and fruit traits can be relevant for plant invasiveness since they are related to dispersal, germination, and fitness. Some seed traits vary along environmental gradients and can be heritable, with the potential to evolve by means of natural selection. Utilizing cross-latitude and reciprocal-transplant experiments, we evaluated the adaptive value of seed thickness as assessed by survival and biomass accumulation in Taraxacum officinale plants. In addition, thickness of a seed and Endosperm to Seed Coat Proportion (ESCP) in a second generation $\left(F_{2}\right)$ was measured to evaluate the heritability of this seed trait. On the other hand, we characterized the genetic variability of the sampled individuals with amplified fragment length polymorphism (AFLP) markers, analyzing its spatial distribution and population structure. Overall, thickness of seed coat (plus wall achene) decreases with latitude, indicating that individuals of $T$. officinale from northern populations have a thicker seed coat than those from southern populations. Germination increased with greater addition of water and seeds from southern localities germinated significantly more than those from the north. Additionally, reciprocal transplants showed significant differences in survival percentage and biomass accumulation among individuals from different localities and moreover, the high correlation between maternal plants and their offspring can be suggesting a high grade of heritability of this trait. Although genetic differentiation was found when was considered all populations, there was no significant differentiation when only was compared the northernmost populations which inhabit in the driest climate conditions. Our results suggest that climatic conditions could affect both, the ESCP and the genetic variability in the invasive T. officinale, suggesting that this seed trait could be indicative of adaptive selection. Thus, colonization along broad geographical gradients in many cases may be the result -in part- for the presence of functional traits as shown in invasive plant species with rapid adaptive capacity.

Keywords: dandelion, clines, heritability, invasive, latitudinal gradient, reciprocal transplant, seed traits 


\section{INTRODUCTION}

Most of invasive species spread in their non-native environments occupying large geographical areas, resulting in plant populations that experience very different climatic conditions (Rejmánek et al., 2005; Molina-Montenegro et al., 2013). Hence, it is logical to assume that the vegetative and reproductive traits of invasive species must experience post-introduction evolution in order to maximize their performance and establishment in those new environments (Chun et al., 2007; Molina-Montenegro et al., 2010). It has been widely suggested that both colonization and invasion success along broad environmental gradients may be partially due to phenotypic plasticity (Sexton et al., 2002; Geng et al., 2007; Molina-Montenegro et al., 2013). In addition, rapid evolution in several traits related with environmental tolerance or resources up-take could also be a relevant factor for invasions (Colautti and Lau, 2015). Nonetheless, a third possible explanation is related with a high pre-existing genetic diversity in the native range and the later filtering of genotypes that could be locally pre-adapted in the new range (see Colautti and Lau, 2015).

The early studies of Baker (1974) and Brown and Marshall (1981) highlighted the idea that rapid evolutionary changes could be an important driving force for biological invasions. More recently, a growing number of studies have provided substantial evidence showing that exotic species recently introduced to new environments can evolve rapidly (Lee, 2002; Maron et al., 2004; Lavergne and Molofsky, 2007; Dlugosh and Parker, 2008; Franks and Weis, 2008; Schierenbeck and Ellstrand, 2009; MolinaMontenegro et al., 2011; Colautti and Lau, 2015). Thus, rapid genetically based adaptation to novel environments might be more important in the ecology of invasions than previously thought. For example, Chun et al. (2007) showed that the invasive Lythrum salicaria (purple loosestrife) exhibited distinct flowering time and flower production characteristics in its introduced range in comparison to its native range, suggesting rapid evolution in several reproductive traits. In addition, Alexander (2013), explaining the invasion success of Lactuca serriola, noted the capacity of non-native populations to rapidly produce phenotypic and genetic adaptive variation along the invaded climate gradient. Furthermore, they proposed that this response could be related to its wide native geographic distribution and the consequent environmental variation.

It has been shown that selective pressures may drive contemporary evolution within exotic plant populations in different ways. In particular, abiotic gradients across the introduced range could impose divergent selection and promote genetically based differentiation among introduced populations (see Maron et al., 2004). A classic manifestation of this would be the evolution of geographic clines, as is often found among plant populations occurring across latitudinal (Santamaría et al., 2003; Prendeville et al., 2013) or altitudinal (Molina-Montenegro and Cavieres, 2010; Kooyers et al., 2015) gradients. However, among cosmopolitan plants little is known about whether these clinally distributed traits have adaptive consequences, this is, if they produce differential expressions of fitness depending on the geographic position along a particular abiotic gradient, and if these traits are heritable.
Seed and fruit traits are critical for dispersal syndromes and mechanisms to cope with environmental stress. They are also sensitive to changes in biotic and abiotic conditions (Baskin and Baskin, 2001; Moles et al., 2005). For example, seed coat thickness can be affected by rainfall, and is inversely related to imbibition capacity and germination rate (Baskin and Baskin, 2001). Additionally, germination rate and carbon mobilization in seed are influenced by seed coat thickness, with a lower germination percentage in seeds with thicker coats (Noodén et al., 1985; Gorim and Asch, 2012). However, in some plant species that have to cope with unpredictable climatic events and low amounts of rain, seeds develop a thicker seed coat in order to have the greatest resistance to extreme drought conditions (Gutterman, 1994). Hence, seed germination shows evidence of adaptive evolution as seed coat thickness is well correlated with germination under different amount of rainfall (Gutterman, 1994). Thus, seed coat thickness plays an important role in reducing seedling mortality risk immediately after germination. Although there is also evidence for a negative relation between seed coat proportion and seed mass (Clements et al., 2002), germination usually depends on the duration of moist periods and rainfall where seeds with thicker seed coats will need higher precipitation to germinate. Thus, as seed traits are variable and may be heritable (Mera et al., 2004), they have the potential to evolve by means of natural selection in a given environment, where a particular seed trait confers higher plant fitness.

In the Taraxacum agg. (aggregate dandelion complex), the dispersal unit is the achene, a fruit which is formed by a single seed with a differentiated seed coat and endosperm, enclosed in a dry (not fleshy) and hard pericarp. In T. officinale, seed coat is fused with achene wall, and it is the achene that is dispersed, acting ecologically as a seed (Tweney and Mogie, 1999). Thus, achene can be considered functionally as the seed for ecological aspects. Seed shape is somewhat similar within the dandelion complex, but populations and ecotypes differ drastically in seed size and coat proportion (Tweney and Mogie, 1999; Honek et al., 2011) with many ecological and evolutionary implications. T. officinale is a perennial herb native from Europe and currently considered to be a very aggressive invasive species almost elsewhere outside its native range (Holm et al., 1997), with a mainly apomictic reproduction but sexual reproduction has been also recorded (van der Hulst et al., 2000). T. officinale in Chile was initially recorded in the city of Santiago in 1870 (Matthei, 1995) and posteriorly in the southern city of Valdivia $\left(39.8^{\circ} \mathrm{S}\right)$ in 1875 . Later this species was recorded in northern cities (La Serena and Caldera) in 1947 and 1949, respectively. Finally, the colonization in southernmost city of this study (Coyhaique) has recently in 1988 (for more details see Molina-Montenegro MA; repository of Ph.D. thesis, Universidad de Concepción) $)^{1}$. Originary from European alpine environments, T. officinale is also widely distributed among different elevations in its native range, particularly associated with disturbed sites (Quiroz et al., 2009; Molina-Montenegro et al., 2011). Contrastingly, in Chile this exotic species has been found growing abundantly in zones with a wide variation in disturbance levels (Cavieres et al., 2005),

\footnotetext{
${ }^{1}$ https://www.udec.cl
} 
being majority of populations triploid with 24 chromosomes (Molina-Montenegro et al., 2013). Moreover, T. officinale has expanded its southern distributional limit (Molina-Montenegro and Naya, 2012) and has colonized higher elevations in the Andes of Central Chile (Cavieres et al., 2008; Molina-Montenegro and Cavieres, 2010). Considering its latitudinal and altitudinal spread, it can be supposed that its invasive capacity is not limited by local conditions.

In the present study we addressed the following questions: (i) does the mean thickness of endosperm and coat (seed coat plus achene wall), and the average proportion between the endosperm and the seed coat (as considered above) vary between populations of T. officinale located along a latitudinal gradient with a marked variation in the rainfall?, (ii) does this variation have any adaptive relevance as assessed by greater germination, survival and biomass?, (iii) are these functional seed traits heritable?, and (iv) Are phenotypic variation and genetic diversity clinally distributed along the precipitation gradient? We assessed these questions by measuring the thickness of both endosperm and of coat, as well as the endosperm to seed coat proportion (ESCP) in individuals of $T$. officinale from 25 populations (distanced among them for $1-1.5 \mathrm{~km}$ ) and clustered in five localities (with five populations each one) distributed along a latitudinal rainfall gradient in Chile. Additionally, we evaluated the germination percentage in seeds from these five localities exposed to different amounts of water. We also evaluated the possible evolutionary change in seed traits and its adaptive consequences through two approaches: first, we evaluated the percentage of seeds germination of populations from the northern and southern limits of the gradient (La Serena and Coyhaique, respectively) through a cross-latitude experiment. Second, we conducted a reciprocal transplant experiment to assess the survival of adults and biomass accumulation with the same set of individuals from two localities (La Serena and Coyhaique). On the other hand, we estimated the heritability of ESCP by analyzing the linear relationship between the expression of this trait in maternal plants and their progeny. Additionally, we assessed the genetic differentiation among populations along the latitudinal gradient and also explored the relationships between genetic differentiation and geographic, trait, and environmental distances. Finally, since T. officinale often reproduces through asexual seed production (apomixis), we also used molecular markers to quantify the proportion of clones within populations, as among populations genetic and seed traits differentiation could be strongly affected by increased clonality due to this reproductive system.

\section{MATERIALS AND METHODS}

\section{Seed Collection}

Seeds of Taraxacum officinale Weber ex. F.H. Wigg. (Asteraceae) were collected in 25 populations from five different locations in Chile: Caldera, La Serena, Valparaiso, Concepción and Coyhaique. This broad latitudinal gradient covers from ca. $27^{\circ} \mathrm{S}$ to ca. $46^{\circ} \mathrm{S}$, including a pronounced rainfall gradient that harbors a mean annual precipitation increase from 41 to $1306 \mathrm{~mm}$ in the sampling sites (Figure 1). All populations were separated at least by $1 \mathrm{~km}$ and at elevations between 0 and $50 \mathrm{~m}$ to reduce altitudinal effects. A range of 5-10 achenes (seeds hereafter) per individual was collected from 20 to 30 sampled plants per population to form the initial seed pool. As $T$. officinale has apomictic reproduction (production of seeds without fertilization), samples were taken from widely separated plants to capture a representative sample of phenotypic variation and genetic of each studied population. First generation plants $\left(F_{1}\right)$ were generated from this initial seed pool and were grown in a greenhouse at Universidad de Concepción, Concepción under natural conditions of light and temperature (day conditions $(08: 00-19: 59 h)=978 \mu \mathrm{mol} \mathrm{m}^{-2} \mathrm{~s}^{-1} \pm 85$ and $18^{\circ} \mathrm{C} \pm 3$, and night conditions $(20: 00-07: 59 h)=122 \mu \mathrm{mol} \mathrm{m}^{-2}$ $\mathrm{s}^{-1} \pm 49$ and $5^{\circ} \mathrm{C} \pm 2$ ). These plants were put in 300 -mL plastic pots filled with potting organic soil and irrigated every 2 days with $50 \mathrm{ml}$ of water. After 5 months these plants produced the achenes that were used to obtain experimental plants $\left(F_{2}\right)$.

\section{Seed Trait Analysis}

We randomly selected five seeds from five different maternal plants $\left(F_{2}\right)$ in each locality (total $n=125$ seeds) to measure the thickness of endosperm and coat, as well as the ESCP. Each seed was cut in half on the equatorial axis with a razor blade. Sectioned seeds were maintained with the section face up using modeling clay and photographed with a digital camera (Motic 3000 Cooled). Each picture was analyzed with specific software for analysis of digital images (Motic Images advance 3.2, Motic Chinese Group, Co., Ltd.). The computer coupled with the digitalization software gave the area and thickness of endosperm and coat of each seed. In addition, the ESCP was calculated as thickness of endosperm (endosperm plus embryo) relative to thickness of coat (seed coat plus achene wall), both in the equatorial section of seed. To assess the variation in the ESCP with latitude, a linear regression was conducted. In addition, differences in the thickness of in both endosperms and coat, and ESCP among localities were assessed with one-way ANOVA and Tukey's HSD post hoc comparison test.

\section{Manipulative Experiment of Germination}

Germination assays were carried out in order to test whether the structural trait analyzed here (ESCP) affected germination under different watering treatments. For each locality, 20 Petri dishes $(100 \times 15 \mathrm{~mm})$ with 40 seeds each were prepared using two layers of wet filter paper $\left(0.3 \mathrm{~g} / \mathrm{m}^{3}\right.$ of density) as substratum in order to avoid loss of humidity (total $n=4000$ seeds). Five Petri dishes (one per population within each locality) were watered with $10,25,50$, or $100 \mathrm{ml}$ of distilled water on two occasions ( $n=100$ Petrie dishes). We selected these amounts of water because they represent typical conditions seeds might encounter in real conditions along the latitudinal rainfall gradient. All Petri dishes were watered once at the beginning of the experiment and placed in a growth chamber with 14/10 day/night photoperiod and $20 \pm 1{ }^{\circ} \mathrm{C}$ constant temperature. Dishes were covered with filter paper, and in order to maintain the differences in water availability for each watering condition, weight of each Petri dish was measured every 3 days throughout experiment. Germination was recorded daily until no new germinated seeds were observed 


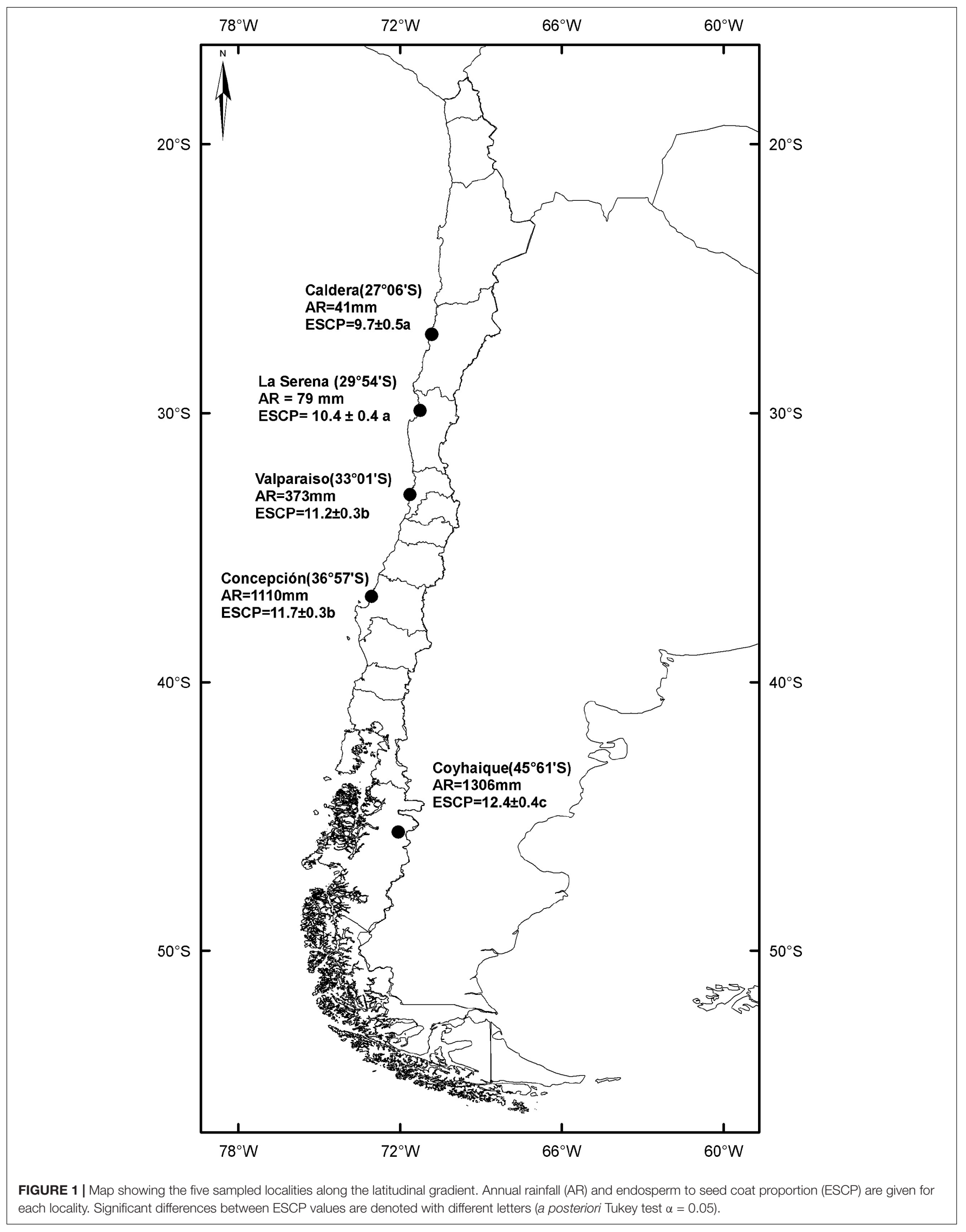


for three consecutive days (day 30). The germination percentages among localities were compared with one-way ANOVA for each watering treatment after arcsine transformation and Tukey's HSD post hoc comparison test.

\section{Cross-Latitude and Reciprocal-Transplant Experiments} Germination Experiment

We conducted a cross-latitude experiment using seeds collected from plants from five populations in La Serena $\left(29^{\circ} 54^{\prime} \mathrm{S}\right)$ and five in Coyhaique $\left(45^{\circ} 61^{\prime} \mathrm{S}\right)$ to investigate possible evolutionary change in endosperm to coat seed proportion and its adaptive consequences. At each of these populations we collected seeds from forty maternal plants and maintained them in paper bags. Forty seeds from each population ( $n=200$ per locality) were collected and bulked previous to buried at $1 \mathrm{~cm}$ of deep in plastic boxes $(20 \times 20 \times 15 \mathrm{~cm})$ arranged in the field. The cross-latitude experiment was conducted in both localities and with seeds from La Serena and Coyhaique. In each locality, we put 20 boxes with ten seeds each, of which half contained seeds from the La Serena, and the other half contained seed from the Coyhaique. In addition, we filled two plastic boxes with soil from each site without addition of seeds in order to assess the presence of $T$. officinale in the seed-bank. Each box was watered once with $10 \mathrm{ml}$ in the locality of La Serena and with $100 \mathrm{ml}$ in the locality of Coyhaique in order to mimic a typical rainfall of 2 days in each locality. Once per week, over 7 weeks, germination was recorded in each box. Germination percentage at 7 weeks of $T$. officinale individuals from both localities was compared by one-way ANOVA. Comparisons were conducted independently for each locality where individuals were transplanted.

\section{Transplant Experiment}

We conducted a reciprocal transplant experiment with plants originated of five populations from the two studied localities (La Serena and Coyhaique) to investigate possible evolutionary change in ESCP and its adaptive consequences. At each of these five populations in each locality, we collected seeds from 40 maternal plants, and germinated in a room with a photon flux density (PFD) of $470( \pm 135) \mu \mathrm{mol} \mathrm{m}^{-2} \mathrm{~s}^{-1}$ at $20^{\circ} \mathrm{C} \pm 2$ in Petri dishes. Five days after the appearance of the first true leaf, seedlings were transferred to growth chamber at $10^{\circ} \mathrm{C}$ with a photon flux density (PFD) of 250 $( \pm 12) \mu \mathrm{mol} \mathrm{m} \mathrm{m}^{-2} \mathrm{~s}^{-1}$ and $16 / 8 \mathrm{~h} \mathrm{light} /$ dark photoperiod. This temperature was chosen because this is an intermediate of annual mean temperature of both localities (Molina-Montenegro et al., 2013). Ten 1-month-old seedlings from each population, each one from a different mother plant, were transplanted directly in a garden plot and randomly assigned following a grid design in both, La Serena and Coyhaique localities ( $n=100$ individuals from each locality). Each group of ten individuals (population) was separated by $1 \mathrm{~m}$ between each point of transplant. The plants were watered once every day only for the first week in order to reduce the death of plants due to the transplants. Once per week, over 10 weeks, survival was recorded for each plant maintaining the recording separated by locality of origin. All surviving plants were harvested after 10 weeks and total plant biomass was obtained after the whole plants were oven-dried at $70^{\circ} \mathrm{C}$ for $72 \mathrm{~h}$. Considering that neither survival percentage [one-way ANOVA $=F_{1,8}=24,56 ; p=0.65$ and $F_{1,8}=16,33 ; p=0.75$ for La Serena and Coyhaique, respectively] nor biomass [one-way ANOVA $=F_{1,8}=41,56 ; p=0.71$ and $F_{1,8}=79,13 ; p=0.21$ for La Serena and Coyhaique, respectively] differed between populations from the same locality of origin, we merged the results by locality. Survival percentage and biomass at 10 weeks of T. officinale individuals from both localities were compared by one-way ANOVA (STATISTICA 7.0). Comparisons were conducted independently for each locality where individuals were transplanted.

\section{Heritability of ESCP}

We estimated the heritability by analyzing the relation between the ESCP of maternal plants and the same trait in their progeny (parent-offspring regression method, sensu Falconer, 1981). It has been shown that seed traits like seed pubescence, shape and thickness have significant heritability (Gómez-González et al., 2011), which might imply a genetic and evolutionary response with probability to change from generation to generation, as classically predicted by the product of the selection index and the heritability estimate (Falconer, 1981).

We focused on the same populations of the germination experiment. From the previous seeds collected in the field in each of 25 populations we generated new plants $\left(F_{2}\right)$ in order to clean of "maternal effects." From this second generation, five maternal plants per population were obtained in order to produce the experimental progeny $\left(F_{3}\right)$. Seeds were germinated in Petri dishes and 2-week-old seedlings were planted in pots with a 1:1 sand:commercial soil mixture. All pots were watered every 3 days at field capacity. Plants were grown in a common environment in a greenhouse until flowering (PFD of $750 \mu \mathrm{mol}$ $\mathrm{m}^{-2} \mathrm{~s}^{-1} \pm 310,50 \mathrm{cc}$ of tap-water per pot every 2 days, and at $24^{\circ} \mathrm{C} \pm 5$ ). Although $T$. officinale has been described as an apomictic species, it is also self-incompatible (Jenniskens, 1984). Seed set also occurs through cross-pollination and hence, pollinator exclusion were needed to accurately estimate the heritability of the ESCP. Therefore, heads were protected from pollinators with a fine, transparent mesh bag $(15 \times 10 \mathrm{~cm})$ with a pore size of $0.9 \times 0.9 \mathrm{~mm}$ until seed maturation $(70-$ 95 days). ESCP of three seeds in three different maternal plants per population and from three seeds (as defined previously) from three $F_{3}$ plants per population were measured (total $n=225$ seeds per mother-progeny group) and compared by a regression analysis (Zar, 1996).

\section{Genetic Diversity and Population Structure}

Total DNA was extracted from dry foliar tissue of plants previously assessed in each locality according to cetyl-trimethylammonium bromide (CTAB) method (Doyle and Doyle, 1987), following the protocol described in Cota-Sánchez et al. (2006). Final DNA concentrations were quantified in a NanoDrop ${ }^{\circledR}$ 
spectrophotometer (ThermoFisher, United States), and their integrities verified by electrophoresis in a $1 \%$ agarose gel. The genetic diversity and population structure were estimated using Amplified Fragment Length Polymorphism (AFLP). The AFLP protocol was performed following the description of Vos et al. (1995). Genomic DNA ( $250 \mathrm{ng}$ ) was digested in a total volume of $25 \mu \mathrm{L}$ using EcoRI (NEB) and MseI (NEB) restriction enzymes (1U each) for $2 \mathrm{~h}$ at $37^{\circ} \mathrm{C}$, followed by $15 \mathrm{~min}$ at $70^{\circ} \mathrm{C}$. The resulting DNA fragments were then ligated with the corresponding EcoRI (5 pmol) and MseI (50 pmol) adapters using T4 DNA ligase (1U) and $1 \times$ ligation buffer (Roche) for $3 \mathrm{~h}$ at $37^{\circ} \mathrm{C}$. Preselective amplification reactions were performed using $1 \mu \mathrm{L}$ of digested-ligated DNA in a total volume of $20 \mu \mathrm{l}$. The mixture contained $1 \times \mathrm{PCR}$ buffer, $1.5 \mathrm{mM} \mathrm{MgCl}$, $0.25 \mathrm{mM}$ of each dNTP, $0.5 \mu \mathrm{M}$ Eco + A primer, $0.5 \mu \mathrm{M}$ MseI + C primer and $1 \mathrm{U}$ of AmpliTaq Gold ${ }^{\circledR}$ DNA polymerase. PCR amplification was carried out with a profile of 20 cycles of denaturation $30 \mathrm{~s}$ at $94^{\circ} \mathrm{C}$, annealing $1 \mathrm{~min}$ at $56^{\circ} \mathrm{C}$, and extension $1 \mathrm{~min}$ at $72^{\circ} \mathrm{C}$. After PCR amplification, amplification products were diluted 1:10 with distilled water and stored at $-10^{\circ} \mathrm{C}$. Selective amplifications were performed using a $1 \mu \mathrm{L}$ of diluted preselective amplification as a template in reactions containing 1x PCR buffer, $1.5 \mathrm{mM} \mathrm{MgCl}_{2}, 0.25 \mathrm{mM}$ of each dNTP, $0.5 \mu \mathrm{M}$ Eco + ANN (fluorescent) primer, $0.5 \mu \mathrm{M}$ Mse + CNNN (or Mse $+\mathrm{CNNN}$ ) primer, and $1 \mathrm{U}$ of Platinum Taq DNA polymerase (Invitrogen Brazil). Selective amplifications started with a touchdown step of $2 \mathrm{~min}$ at $94^{\circ} \mathrm{C}$, then 10 cycles of $30 \mathrm{~s}$ at $94^{\circ} \mathrm{C}, 30 \mathrm{~s}$ at $65^{\circ} \mathrm{C}\left(1^{\circ} \mathrm{C}\right.$ decrease each cycle $)$ and $1 \mathrm{~min}$ at $72^{\circ} \mathrm{C}$. This was followed by 30 cycles of $30 \mathrm{~s}$ at $94^{\circ} \mathrm{C}, 30 \mathrm{~s}$ at $56^{\circ} \mathrm{C}$ and $1 \mathrm{~min}$ at $72^{\circ} \mathrm{C}$, ending with a final elongation of $30 \mathrm{~min}$ at $72^{\circ} \mathrm{C}$.

Following Majesky et al. (2012), we used three selective primers combinations: $\mathrm{E}+\mathrm{AGC} / \mathrm{Mse}+\mathrm{CAAT}$, $\mathrm{Eco}+\mathrm{AAT} / \mathrm{Mse}+\mathrm{CAAC}$ and EcoAGC/Mse + GATG that produced 85, 61 and 50 fragments, respectively. All profiles were run in an automatic sequencer (Applied Biosystems 3120, 16 capillaries) at the Molecular Biology Laboratory of the Pontificia Universidad Católica de Chile. For each pair of primers combination, fragments with sizes between 80 and $450 \mathrm{bp}$, and intensities $>200$, were first selected using GeneMarker 2.4.0 (Soft Genetics). These fragments were coded in a presence/absence (1/0) matrix. The chosen fragments were, besides polymorphic, present in no less than 5\% (nor more than 95\%) of the individuals, and error rates of replication were lower than $8 \%$. AMaRe (AFLP Matrix Reduction) method, outlined in Kück et al. (2012), was used to calculate reliability and error rate of the matrix. The average unbiased expected heterozigosity $\left(H_{E}\right)$, percentage of polymorphic loci (\% PL; a loci was considered polymorphic if at least in $5 \%$ of the sample the less frequent state was observed) and Shannon's index of diversity (I) were estimated using GENALEX (Peakall and Smouse, 2006).

Population genetic structure was investigated though Discriminant Analysis of Principal Components (DAPC) using the adegenet R-package (Jombart, 2008; Jombart et al., 2010), and hierarchical analysis of molecular variation (AMOVA). First, DAPC analysis was applied to the AFLP data to visualize the potential clustering of individuals, which together with the pair-wise $F_{S T}$ values between localities, was used as the criteria to define a population structure to be tested in the analysis of molecular variance (AMOVA). Both, $F_{S T}$ and AMOVA analysis were performed in Arlequin 3.5 (Excoffier et al., 1992), all other analysis were carried out on the $\mathrm{R}$ language and environment for statistical computing v3.1.3 (R Core Team, 2015).

We explored the relationships between genetic differentiation among localities (pairwise $F_{S T}$ ) and geographical distance (Euclidean), differences in mean annual rainfall and differences in seed coat to endosperm proportion. The level of correlation between pairs of distance matrices was estimated using Mantel test's (Mantel, 1967). The significance for each correlation coefficient between matrix pairs was obtained from the distribution of 9999 randomizations as supported by the "ade4" R-package (Dray et al., 2007).

\section{Clonality Assessment}

Asexual reproduction (agamospermy) is common in dandelions (Asker and Jerling, 1992). Thus, in its native range of distribution natural populations can be formed either by co-occurring sexual diploids and apomictic triploids, or by exclusively by apomictic triploids (Asker and Jerling, 1992; van der Hulst et al., 2000; Majesky et al., 2012). To assess whether the studied populations are formed by few successful clonal lineages or by several multi-locus lineages, we estimated the extent of clonal reproduction in our AFLP dataset using the software GenoDive 2.0b17 (Meirmans and Van Tienderen, 2004). We choose GenoDive because it has been extensively employed to estimate clonal diversity on marine organisms (e.g., Blouin and Brawley, 2012) and plants (e.g., Lasso, 2008; de Witte et al., 2012) using AFLP markers. Briefly, GenoDive uses a "threshold" of genetic distance between pairs of individuals to distinguish clones from non-clones. Below that threshold of genetic dissimilarity, samples are considered to represent a single clone. In other words, this threshold indicates the maximum distance that is allowed between a pair of individuals to still be considered clonemates (individuals from the same clonal lineage). GenoDive assumes that random mating within populations, i.e., its tests whether the allelic frequencies deviate from these that are expected under random mating. To do this, GenoDive tests the null hypothesis that the observed clonal diversity is due to sexual reproduction by randomizing alleles over individuals and comparing the observed clonal diversity with that of the randomized dataset uses (Gomez and Carvalho, 2000). It is important to note that other processes than asexual reproduction such as self-fertilization can also lead to identical genotypes, and therefore, under random mating clones can also be produced. Since scoring errors and mutations may cause individuals from the same clonemate to have a pairwise distance larger than zero, choosing an appropriate threshold is crucial to perform accurate clonal assignments (Rogstad et al., 2002; Lasso, 2008). While too low thresholds overestimates the estimates of clonal diversity, choosing this value too high results in its underestimation.

Our dataset consisted of a total of 89 individuals from 5 populations genotyped with AFLP's (Supplementary Table S1). To reduce the scoring error rates in clone assignment we previously eliminated from our dataset all loci containing missing 
genotypes (45 loci). In addition, scoring errors were checked using the software AMARE (Kück et al., 2012), This analysis revealed that scoring error rate was reduced from $5 \%$ in the total data set (196 loci) to $2 \%$ in the subset used to estimate the levels of clonality (151 loci). After this procedure we selected this subset of 151 AFLP bands to evaluate clonal diversity. Specifically we made a clone assignment analysis to determine the number of multilocus lineages (MLLs) within each population and the clonal fraction (i.e., the ratio of MLLs to samples) which was calculated as ( $N-$ MLLs) / N. The analyses were run considering the following parameters: (i) a threshold of 6 loci (i.e., pairs of individuals that differed in a maximum of 6 loci were considered as clonemates), (ii) an infinite allele model, (iii) 1,000 permutations and (iv) randomizing of alleles over individuals within populations, and over individuals over all populations. Since most studies to date have reported threshold values between 2 and 4\% (e.g., van der Hulst et al., 2000; Douhovnikoff and Dodd, 2003; Douhovnikoff et al., 2004), we used a threshold of 6 for our dataset as it represents a $4 \%(6 / 151$ loci $=0.039)$ of AFLP genetic dissimilarity between pairs of individuals.

\section{RESULTS}

\section{Seed Trait Analysis}

The ESCP showed a strong and significant positive relationship with mean annual precipitation $\left(r^{2}=0.95 ; p<0.01\right.$, Figure 1). Contrarily, the thickness of endosperm (endosperm plus embryo) was not different $\left(F_{4,120}=11.17 ; p=0.79\right)$ between seeds of individuals from all localities (Figure 2A). On the other hand, seed coat thickness showed a significant variation with latitude, with $T$. officinale from northern populations having a thicker seed coat than those from southern populations $\left(F_{4,120}=553.43\right.$; $p<0.001$, Figure 2B).

\section{Manipulative Experiment of Germination}

Germination percentage increased considerably in the treatments with greater addition of water (Figure 3). Seeds from southern localities showed significantly higher percentage of germination $\left(F_{1,4}=32.53 ; p=0.02\right)$ than those from the northern ones (Figure 3). This trend was more pronounced in the treatment with a lower water addition (10 ml: $p<0.001 ; 25 \mathrm{ml}: p<0.001$; $50 \mathrm{ml}: p<0.01 ; 100 \mathrm{ml}: p=0.88)$.

\section{Cross-Latitude and Reciprocal-Transplant Experiments}

Overall, the germination experiment showed that germination percentage was higher in those seeds with slimmer seed coat and in those located in Coyhaique. Specifically, seeds produced by T. officinale individuals from Coyhaique had significantly higher germination percentage $\left(F_{1,8}=64.35 ; p<0.001\right)$ than those from La Serena when they were buried in La Serena (Figure 4). In contrast, seeds of $T$. officinale individuals from both localities when were buried in Coyhaique showed similar germination percentage $\left(F_{1,8}=2.57 ; p=0.29\right.$, Figure 4).

On the other hand, the reciprocal transplant experiment showed that both survival and biomass were similar among

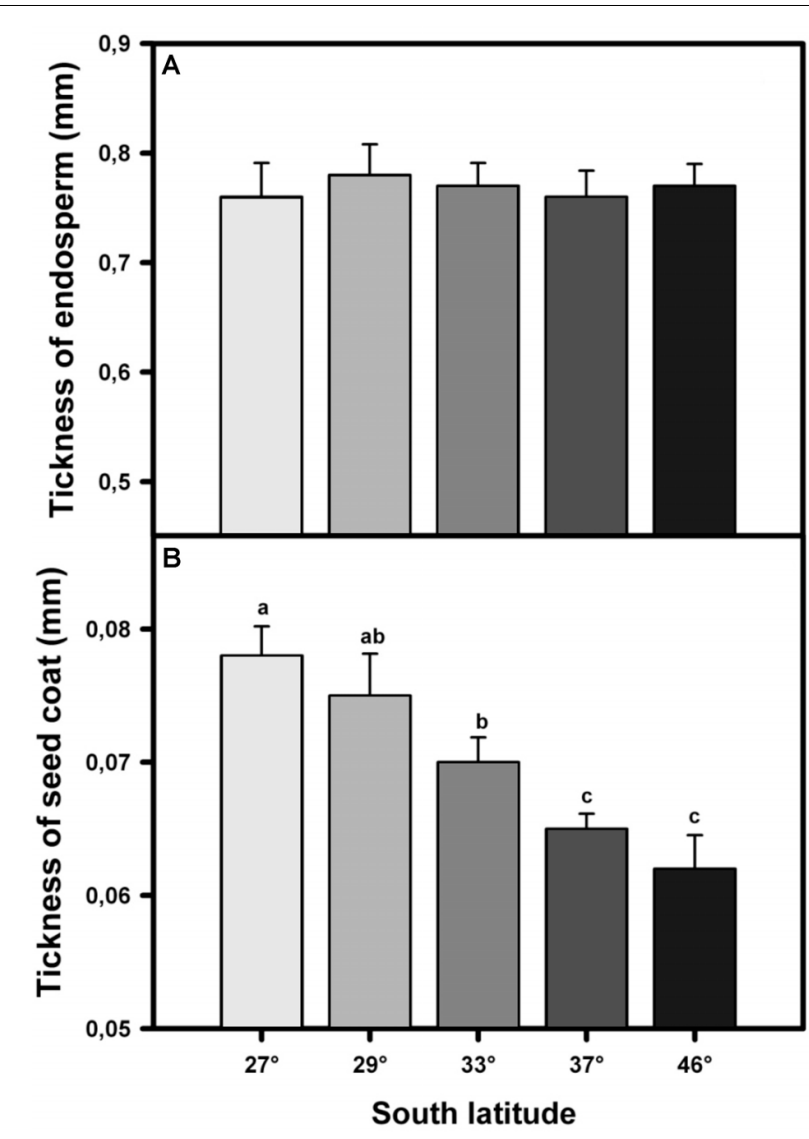

FIGURE 2 | Mean values ( \pm 2 SE) of thickness of endosperm (A) and seed coat (B) in seeds of Taraxacum officinale collected from five localities along a latitudinal gradient. Significant differences between localities are denoted with different letters (a posteriori Tukey test $\alpha=0.05$ ).

populations within each origin but differed between La Serena and Coyhaique (Figure 4). Specifically, T. officinale individuals from La Serena had significantly higher survival percentage $\left(F_{1,16}=108.1 ; p<0.001\right)$ than those from Coyhaique (Figure 4). Interaction between site of transplant and origin of plants $(\mathrm{S} \times \mathrm{O})$ was significant $\left(F_{1,16}=241.8 ; p<0.001\right)$, since individuals of Coyhaique had lower survival than those from La Serena but only when they were transplanted in La Serena (Figure 4). In addition, the biomass accumulation in $T$. officinale individuals from both origins was significantly greater when were grew-up in Coyhaique $\left(F_{1,16}=91.1 ; p<0.001\right.$; Figure 4). Interaction $(\mathrm{S} \times \mathrm{O})$ was significant $\left(F_{1,16}=5.7 ; p<0.001\right)$, since individuals of Coyhaique had higher biomass accumulation than those from La Serena but only when they grew-up in Coyhaique (Figure 4).

\section{Heritability of Seed Trait}

The expression of the ESCP showed a significant positive relationship between maternal plants and their progenies $\left(r^{2}=0.88 ; p<0.001\right)$, suggesting that this trait is heritable and has the potential to evolve by natural selection (Figure 5). 


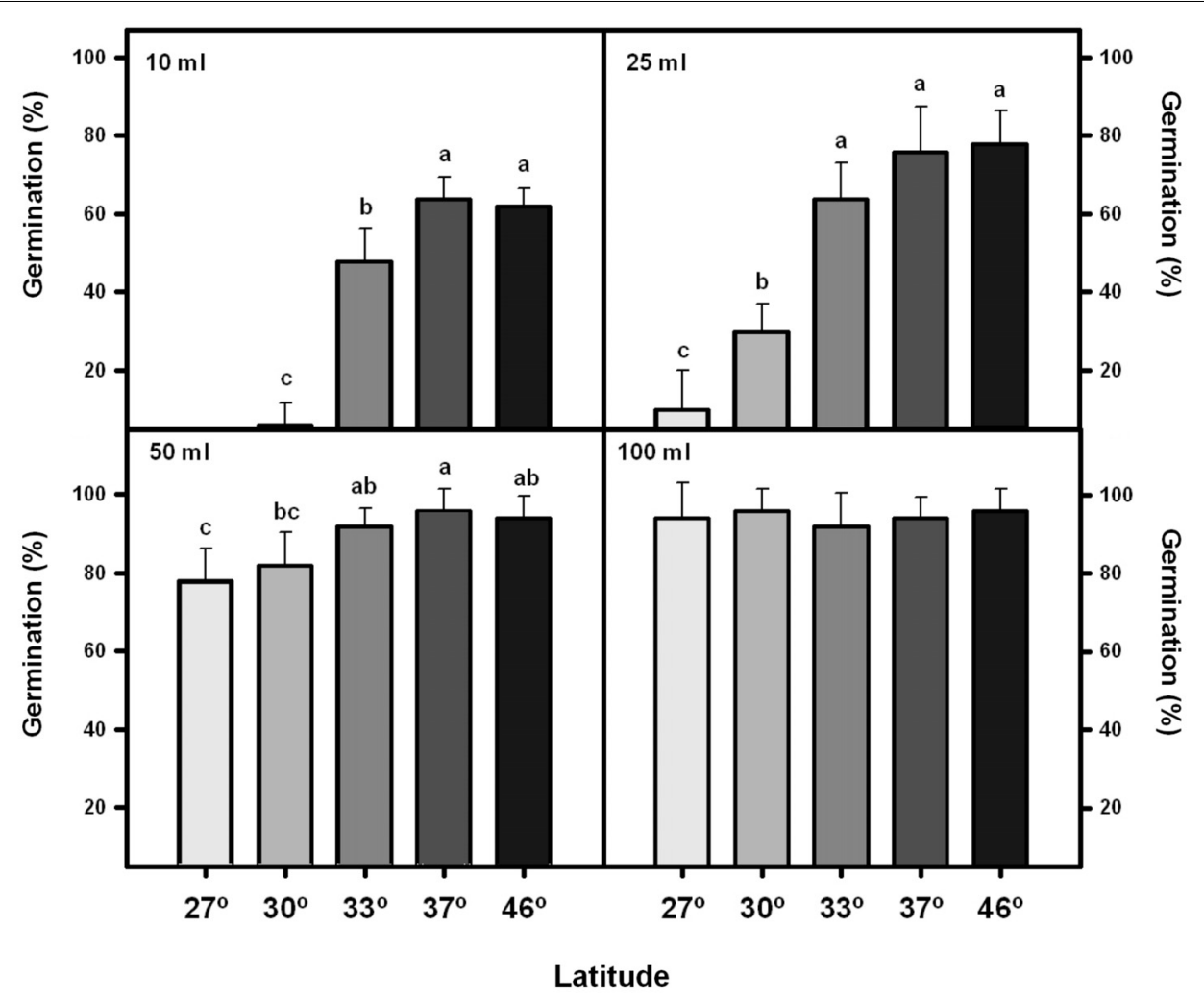

FIGURE 3 | Germination percentage of Taraxacum officinale seeds collected from five localities along a latitudinal gradient and exposed to different amounts of water irrigation treatments. Mean values $( \pm 2 \mathrm{SE}$ ) in germination of five populations of every locality along the latitudinal gradient are shown. Significant differences between localities are denoted with different letters (a posteriori Tukey test $\alpha=0.05$ ).

\section{Genetic Diversity and Relationships with Environmental Variables}

Overall, the levels of within-locality genetic diversity were moderate. The mean unbiased expected heterozigosity $\left(H_{e}\right)$ was $0.183( \pm 0.007)$, ranging from $0.129( \pm 0.014)$ in Valparaiso to $0.229( \pm 0.015)$ in Caldera. Similarly, the mean percentage of PL was $52.4 \%$, ranging from $39.2 \%$ in Valparaiso to $71.3 \%$ in Caldera. None of these estimators were correlated with the environment, latitude or seed traits (Table 1).

The Discriminant Analysis of Principal Components (DAPC) analysis revealed four clusters with a major disruption between north-south localities (Figure 6). In a mixed cluster the northern localities of Caldera and La Serena denote their close genetic relationship, but also a strong differentiation from the rest of individuals. In the other hand, individuals from the more southern localities of Valparaiso, Concepcion and Coyhaique, albeit each one appeared as isolated groups, they are all opposed to the northern localities (Figure 6). Consistently, genetic differentiation (pairwise $F_{S T}$ ) between Caldera and La Serena was not significantly different from zero, averaging 0.56 and ranging from 0.31 between Valparaiso and Coyhaique localities, to 0.82 between Valparaiso and La Serena (Figure 6). A four-localities structure, following the DAPC and $F_{S T}$ results, was proposed for testing in the analysis of molecular variance (AMOVA): Valparaiso, Concepción and Coyhaique as individual groups, and
Caldera and La Serena joined in the fourth one. This analysis revealed a strong locality structure $\left(F_{S T}=0.614, p<0.001\right)$ with the remaining $\sim 38 \%$ of the observed variation as within-locality variation.

Finally, despite high levels of correlation were found between the geographical, environmental and trait distance matrices among localities (Figure 7), there was no relationship between any of them and the matrix of pairwise genetic distances, as showed by the significance of the Mantel test coefficients (Table 1). Nevertheless, the Mantel correlation $(r \mathrm{M}=-0.69$, $p=0.074$ ) suggest an interesting trend between the genetic and the phenotypic traits (Figure 7).

\section{Clonality Assessment}

Considering all populations, 75 out of the 89 samples were unique multi locus lineages (MLLs) Thus, the average clonal fraction (for the entire dataset) was 0.16 , ranging from 0.11 in Caldera to 0.20 in Coyhaique (Supplementary Table S1). Since clones were found in all populations, the hypothesis of random mating was not met (Supplementary Table S1). The number of clone pairs in the entire dataset was 11, ranging from 1 in Valparaiso to 3 in La Serena and Coyhaique (Supplementary Table S2). Although apomixis (clonal reproduction through seeds) is an important mode of reproduction in dandelions, our results indicate asexual and sexual reproduction in Chilean dandelions. 

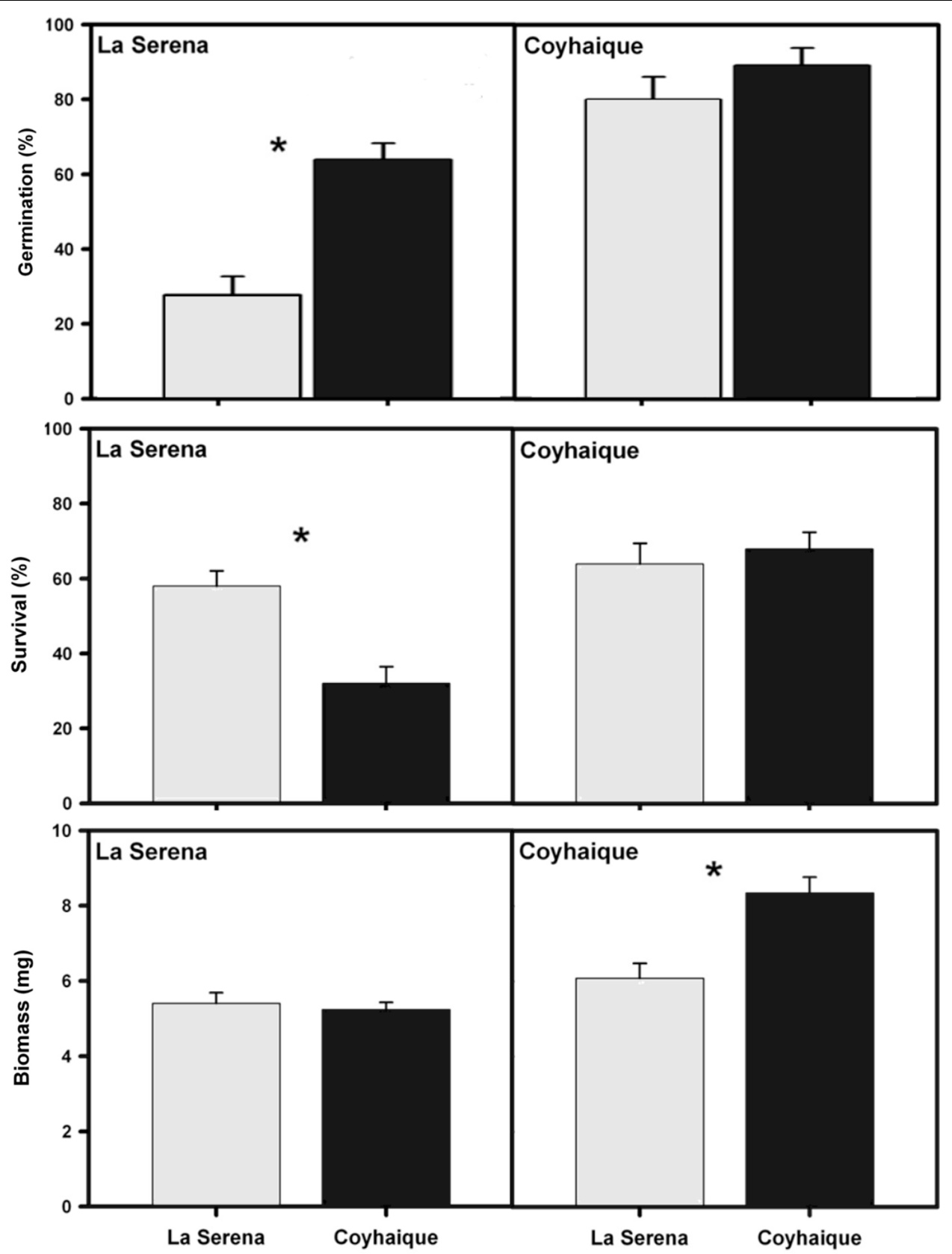

FIGURE 4 | Mean values ( \pm 2 SE) of germination percentage, survival percentage and total biomass (mg of dry weight per plant) of $T$. officinale individuals from La Serena and Coyhaique and put in both La Serena and Coyhaique. The locality name in the upper-left corner of each box denotes the place where transplants were made. Asterisk indicates significant differences.

This result is consistent with the findings of previous studies addressing the importance of asexual and sexual reproduction in T. officinale. For instance, van der Hulst et al. (2000) studying a single population of triploid dandelions from Jutland (Denmark) found that, although asexual reproduction (apomictic) result in overrepresented widespread genotypes, sexual recombination has substantial contribution to genetic variation. Interestingly, the clonal fraction found by van der Hulst et al. (2000), was greater (0.59) than that found in this study (0.16), suggesting higher rates of sexual reproduction in Chilean dandelions. In a recent study, Majesky et al. (2012) found low levels of genotypic diversity (high proportion of clones) in European dandelions. However, they also found evidence of mutation and sexual recombination, suggesting that clones can be originated from hybridization between sexual (diploids) and apomictic (triploids). Therefore, clonality analyses indicate that Chilean populations of dandelions consist of multiple clones, and there is substantial genetic variation for natural selection act upon. 


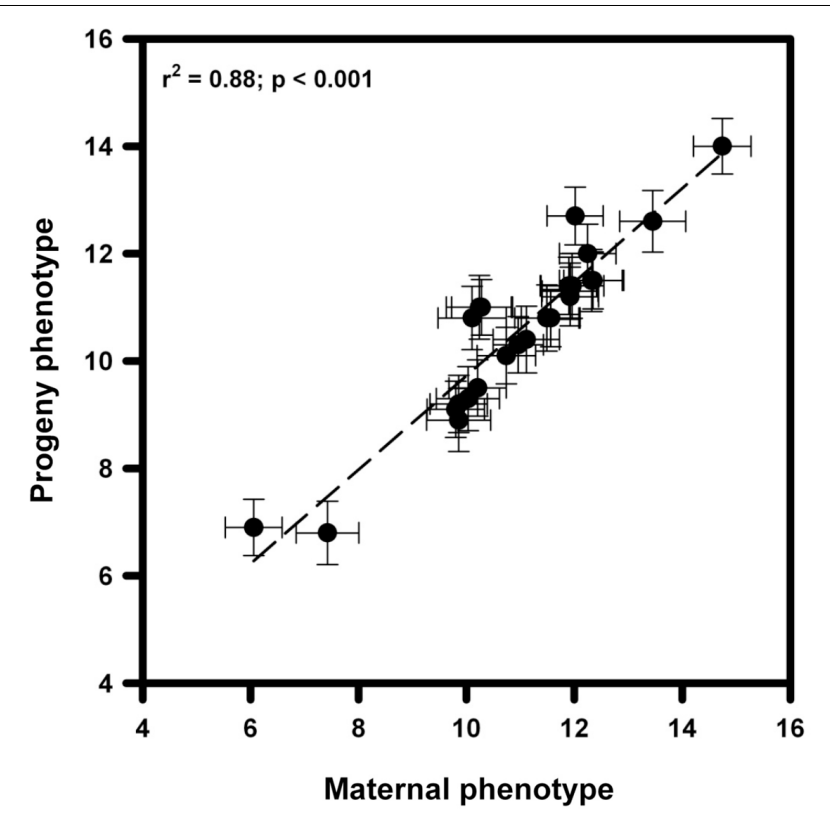

FIGURE 5 | Heritability of the ESCP in Taraxacum officinale seeds from 25 populations belonging to five localities distributed along a latitudinal gradient. Means of the relationship between the maternal phenotype and the offspring phenotype of nine seeds per population are shown.

TABLE 1 | Summary of Mantel correlation coefficients between the studied seed trait (endosperm to coat proportion) and environmental, genetic, and geographic distance matrices among populations.

\begin{tabular}{lcccr}
\hline vs. & Genetic & Geographic & Environmental & Trait \\
\hline Genetic & - & & \\
Geographic & $0.32^{n s}$ & - & \\
Environmental & $0.50^{n s}$ & $0.76^{* *}$ & - & \\
Trait & $0.55^{n s}$ & $0.82^{*}$ & $0.74^{*}$ & -
\end{tabular}

The significance of the standardized Mantel statistic was tested by permutation. ${ }^{n s} p>0.05 ;{ }^{*} p<0.05,{ }^{* *} p<0.01$.

\section{DISCUSSION}

Here, we show evidence of adaptation and heritability in seed coat to endosperm proportion of the seeds of the invasive T. officinale that suggests a rapid differentiation of this plant species into ecotypes adapted to different rainfall levels. This may help to explain why $T$. officinale can successfully colonize broad spatial range with contrasting environmental conditions.

Most of studies that have assessed key invasiveness traits have compared the fitness and functional traits between invasive and native species (van Kleunen et al., 2010; Godoy et al., 2011; Molina-Montenegro et al., 2012b, 2013). In contrast, differences in plant performance among population within non-native range have received much less attention, despite the fact that genetic variation may be critical for invasiveness potential (Meyer and Allen, 1999; Neuffer and Hurka, 1999; Vellend et al., 2010; Molina-Montenegro et al., 2011, 2013). Recent literature has highlighted the evolutionary dimension of biological invasions (e.g., Bossdorf et al., 2005; Thorpe et al., 2011; Colautti and Lau, 2015). However, the discussion on how local adaptation influences the spread of invasive species has been highly speculative, as it is based on a limited number of quantitative studies (but see García-Ramos and Rodríguez, 2002; Urbanski et al., 2012; Colautti and Barrett, 2013; Molina-Montenegro et al., 2010, 2013; Colautti and Lau, 2015). Our results show empirical evidence about the variation in a seed trait with adaptive value in an invasive plant species. This information could be used for management of invasive species and for the identification of potential new invaders. In fact, some studies have identified several traits related with physiology, environmental tolerance, fitness and/or life-history traits, higher represented in invasive species than natives one (Pysek and Richardson, 2007; MolinaMontenegro et al., 2012a). Thus, to recognize several traits (e.g., those related with seeds) that enhance the environmental tolerance, survival or spread capacity, could be an early indicator to estimate the potential of invasion for a given set of species.

Several biological studies (reviewed in Phillips et al., 2006) have documented that classical models may underestimate the speed of invasion process, suggesting that evolutionary responses to novel environments might speed up invasions. Namely, the evolution of morphology and life-history traits can have strong impact on the invasion success and expansion of invading species (Phillips et al., 2006; Molina-Montenegro et al., 2012a; Hulme and Barrett, 2013; Pysek et al., 2015). For example, Maron et al. (2004) found a clinal variation in several morphological and functional traits in the introduced populations of Hypericum perforatum, suggesting that these variations can help explain the quick spread of this invasive species in North America. In this context, the study of traits involved in the adaptation to a rainfall gradient, such as variation in seed coat thickness found in T. officinale, is pivotal to understand the adaptation and evolution of invasive plant species.

In seminal studies of biological invasions, evolutionary biologists postulated that genetic variation and adaptive evolution through natural selection are involved in the success of invading species (Baker, 1965; Mayr, 1965). A growing number of studies have shown that putatively adaptive traits have evolved in introduced populations (Rogers and Siemann, 2004; MolinaMontenegro et al., 2011; Colautti and Lau, 2015), sometimes quite rapidly (e.g., less than 10 years) (Reznick and Ghalambor, 2001; Leger and Rice, 2007; Whitney and Gabler, 2008). Continuous spread of $T$. officinale has probably taken place since the first recorded occurrence in 1870 and even that some populations are far from this city, it seems unlikely that this species has been present for more than 50 years in all localities considered here. Notwithstanding of this short period of time, some of these populations have shown a significant differentiation in the mean value of the assessed seed trait among $T$. officinale individuals from the native range and the invaded localities in Chile. For instance, seeds of T. officinale individuals collected in the native range $(2600 \mathrm{~m}$ a.s.l., showed an endosperm to seed coat proportion $=12.2 \pm 0.3$; endosperm $=0.76 \pm 0.11 \mathrm{~mm}$; and seed coat thickness $=0.062 \pm 0.06 \mathrm{~mm}$ ). These values are similar to those found in the southern populations of Chile, where the annual rainfall is similar to the native range (annual 


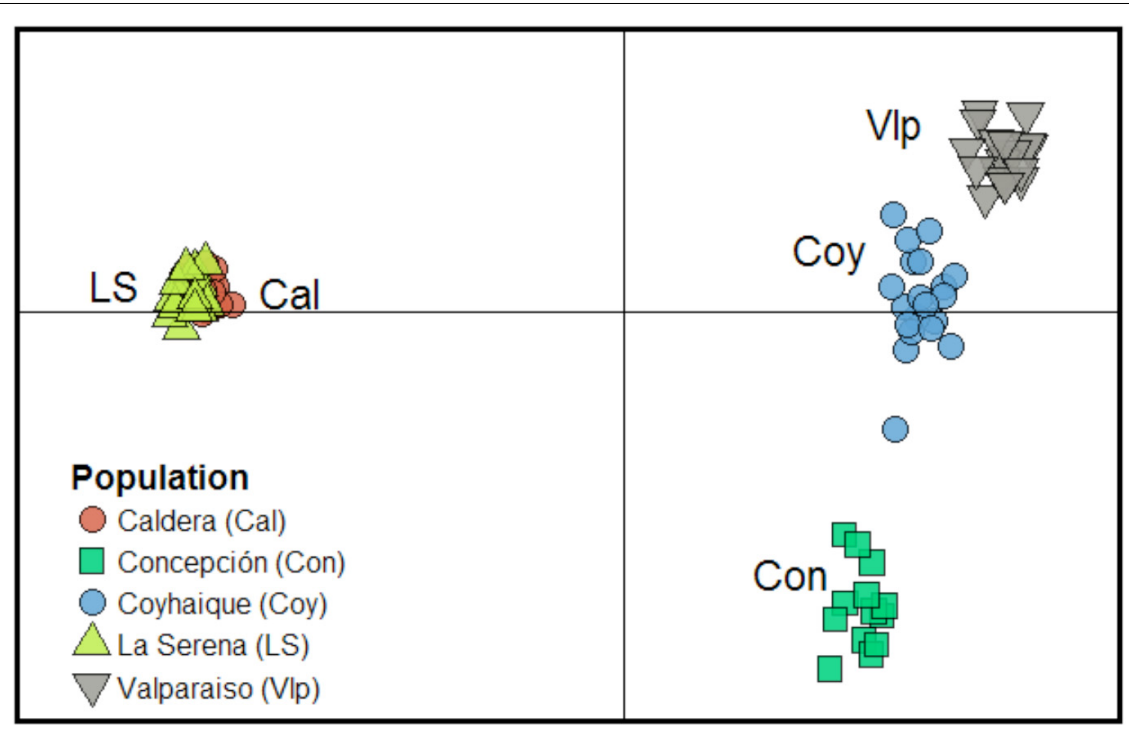

FIGURE 6 | Results of the DAPC analysis over the 196 AFLP loci genotyped for 90 T. officinale individuals. Samples from five localities are included (Caldera, La Serena, Valparaiso, Concepción and Coyhaique) along the latitudinal gradient. The first two discriminant functions show that most genetic variation is explained by four clusters, with a clear divergence between northern and southern populations.

rainfall $=1560 \mathrm{~mm}$, Molina-Montenegro et al., 2011), but quite different of those populations in Chile with contrasting rainfall amounts. Thus, our results suggest that individuals of T. officinale arrived to Chile had to adapt several functional traits (e.g., seed coat) according the climate conditions experienced in each locality in order to germinate and establish permanent populations.

The high variability in the expression of the seed traits assessed among the Chilean T. officinale populations appeared to be highly related to experienced variation in rainfall. But moreover, as they also show evidence for genetic differentiation and heritability in those traits, the potential to adapt to local environmental conditions and thus evolve in their new habitats rapidly, is not rule out for this species. This could be observed in the two northern locations, Caldera $\left(27^{\circ} 05^{\prime} \mathrm{S}\right)$ and La Serena $\left(29^{\circ} 54^{\prime} \mathrm{S}\right)$, despite being $402 \mathrm{~km}$ apart, their similar extremely dry conditions seem to greatly influence the genetic composition of $T$. officinale individuals. Currently, similar genotypes are present in both localities (pair-wise $F_{S T}=0.002$ ) such as to consider them as belonging to the same population (Frankham et al., 2002), even when both present high levels of genetic diversity (71 and $54 \%$ of $\mathrm{PL}$, respectively). Interestingly, at a similar distance $(439 \mathrm{~km})$ toward the south, in Valparaiso $\left(33^{\circ} 02^{\prime} \mathrm{S}\right)$, significant differences are already observable in both, seed traits and genetic composition. In this sense, the most evident genetic disruption seems to occur between the two northern populations and the rest of individuals. This may suggest that the $\sim 371 \mathrm{~mm}$ of Valparaiso's rainfall, in comparison with $\sim 41 \mathrm{~mm}$ and $\sim 79 \mathrm{~mm}$ of Caldera and La Serena, could be enough to relax the environmental filter that maintain the genetic similarity within the northern individuals of T. officinale. Indeed, all southern locations appeared genetically differentiated between them; however, the spatial pattern for their genetic divergence was not latitudinally oriented, suggesting that genotypes are only partially linked to the clinal variation observed in the seed structure among the studied populations of $T$. officinale. Nevertheless, is not possible discard that different historical patterns of introduction can explain these differences also. In fact, the history of introduction in Chile suggests more than only one event did occur; even these introductions appear to be simultaneously in many localities spatially distanced. Thus, it is possible to propose two alternative hypotheses: first, individuals of $T$. officinale arrived to new range and once established, the environment did act as selective pressure, filtering some traits (e.g., seed coat), favoring individuals with thicker and thinner seed coat in driest and wetter sites, respectively. Second, T. officinale was introduced repeatedly from multiple origins, and only those genotypes that were pre-adapted to the new environment could maintain themselves over time. For example, those genotypes in the northern populations of Chile may have received propagules from a dry locality in its native range, or even from other dry sites of the non-native range (e.g., California). However, the high genetic similarity between the populations of these two localities suggests that they were originated from the same colonization event. Future studies should address the hypothesis of multiple introduction events of $T$. officinale, by mean of phylogeographic approaches, to understand the evolutionary processes of differentiation in its introduced range (see, Leger and Rice, 2007).

Rapid adaptive evolution has been advocated as an important mechanism involved in successful invasion by exotic plant species (Maron et al., 2004; Sax et al., 2007; Cano et al., 2008; Colautti and Lau, 2015). When species are introduced into a new region they may face novel selective regimes, under which, shifts in genetically based phenotypic traits may increase the fitness of individuals (Suarez and Tsutsui, 2008). Convincing evidence of 

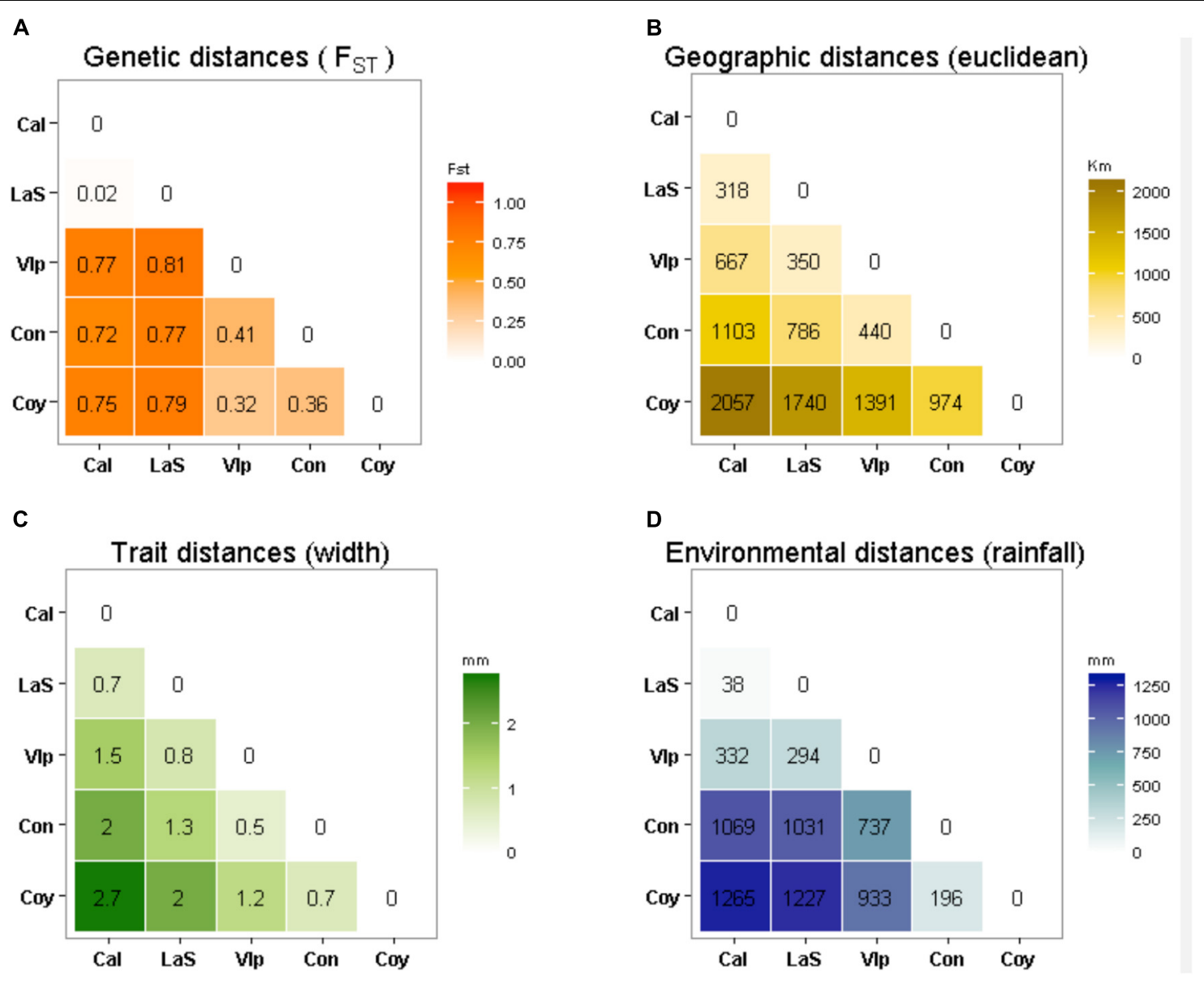

FIGURE 7 | Matrix of genetic (A), geographic (B), trait (C) and environmental (D) distances between T. officinale individuals from five localities (Caldera, La Serena, Valparaiso, Concepción and Coyhaique), along the latitudinal gradient. With the exception of the pairwise $F_{S T}$ value between Caldera and La Serena $\left(F_{S T}=0.002\right)$, all other genetic distances were statistically significant $(p<0.05)$.

rapid adaptive evolution has been reported in some invasive animals (Phillips et al., 2006; Urbanski et al., 2012), but such evidence has been seldom documented in invasive plants (but see, Barrett et al., 2008). Here, we found a likely example for adaptive evolution in an invasive plant species, where the thickness of seed coat is modified for changes in precipitation, affecting the percentage of germination and enhancing the probability of seedling survival in $T$. officinale according to the abiotic conditions of each population. Thus, if fitness-related traits measured in $T$. officinale are driven by differences in endosperm to seed-coat proportion and seed coat thickness, these differences may be an adaptive response due to differential resource allocation and fitness in different localities, or may potentially reflect divergent natural selection (sensu Haig and Westoby, 1990). Reciprocal transplant experiment indicates that seed coat thickness, have a strong adaptive effect, because they maximize the survival in arid environments and improve growth in moist environments, having a thicker and slimmer seed coat respectively. Hence, the rapid adaptive evolution and high heritability of ESCP allow $T$. officinale to successfully colonize and spread in habitats with different environmental conditions. Nevertheless, this capacity could be also related to other functional seed traits not analyzed in this study, for which it remains to be tested.

Considering the apomictic (asexual reproduction through seeds) reproductive mode of $T$. officinale, any relevant trait for plant fitness might be quickly fixed in stressful environments. This trend is evidenced in our results, where individuals from northern (dryer) population showed thicker coated seeds than those from wetter southern populations, and this seed trait was correlated with higher fitness when were sown in site with abiotic conditions similar to those found in their origin as showed by survival experiments. Thus, seeds with thicker coat will be successful in sites with low precipitations in order to avoid germination when abiotic conditions are not suitable. Precipitation here are scarce and seeds will need to germinate only when a certain amount of water is available, avoiding high seedling mortality. On the other side, populations growing in the southern sites produced seeds with a slim seed coat since with water availability for a good germination and early seedling growth is not limiting. The adaptive value of seed coat thickness was highlighted when the germination percentage 
of seeds from rainy population was significantly higher than the driest population, but the mortality was more pronounced in the rainy population. On the other hand, although both populations showed high germination percentage when sown in moist environment, those from the rainy sites showed significantly higher growth than dryer sites. Thus, ours results suggest that the clinal variation in the seed coat thickness of T. officinale populations has an adaptive value, positive impacting colonization and invasion of broad environmental gradients.

Alternatively, broadly distributed plants species must deal with a wide range of environmental conditions and respond to challenges imposed by environmental conditions by means of phenotypic plasticity (Valladares et al., 2014). Ecological theory predicts that phenotypic plasticity should be one of the main adaptive mechanisms in heterogeneous or changing environments as those found along a latitudinal gradient. In fact, the relative importance of phenotypic plasticity in morpho-physiological and fitness-related traits to explain the ample ecological breadth in $T$. officinale has been previously addressed (Molina-Montenegro et al., 2010, 2012a, 2013, 2018). Nevertheless, in the present study we discard the plasticity as a key factor to explain the current patterns in the seed trait assessed. First, previous to began the laboratory and field experiments we "clean" the maternal effects using seeds from a second generation $\left(F_{2}\right)$ and to assess the level of heritability we used a third generation $\left(F_{3}\right)$. In both cases, all "maternal plants" were growth under similar conditions but its seeds maintained the differences in the morphologic characteristics, suggesting the at least the seed-coat thickness is a not plastic trait.

Since rainfall regimes are changing worldwide due to global change processes (IPCC, 2013), it is essential that we understand how plant populations can respond to temporally variable conditions and rapidly adapt and colonize new environments. In a global change scenario, new environments would be available

\section{REFERENCES}

Alexander, J. M. (2013). Evolution under changing climates: climatic niche stasis despite rapid evolution in a non-native plant. Proc. R. Soc. Lond. B 280, 20131446. doi: 10.1098/rspb.2013.1446

Asker, S. E., and Jerling, L. (1992). Apomixis in Plants. Boca Raton, FL: CRC-Press.

Baker, H. (1974). The evolution of weeds. Annu. Rev. Ecol. Evol. Syst. 5, 1-24. doi: 10.1146/annurev.es.05.110174.000245

Baker, H. G. (1965). "Characteristics and modes of origin of weeds," in The Genetics of Colonizing Species, eds H. G. Baker and G. L. Stebbins (New York, NY: Academic Press), 147-169.

Barrett, S. C. H., Colautti, R. I., and Eckert, C. G. (2008). Plant reproductive systems and evolution during biological invasion. Mol. Ecol. 17, 373-383. doi: 10.1111/j.1365-294X.2007.03503.x

Baskin, C. C., and Baskin, J. M. (2001). Seeds, Ecology, Biogeography, and Evolution of Dormancy and Germination. San Dieg, CA: Academic Press.

Blouin, N. A., and Brawley, S. H. (2012). An AFLP-based test of clonality in widespread, putatively asexual populations of Porphyra umbilicalis (Rhodophyta) in the Northwest Atlantic with an in silico analysis for bacterial contamination. Mar. Biol. 159, 2723-2729. doi: 10.1007/s00227-012-2029-z

Bossdorf, O., Auge, H., Lafuma, L., Rogers, W. E., Siemann, E., and Prati, D. (2005). Phenotypic and genetic differentiation between native and introduced plant populations. Oecologia 144, 1-11. doi: 10.1007/s00442-005-0070-z for shift or expand the native and/or introduced range by part of species that have the capacity to adapt rapidly. $T$. officinale seems to have a successful strategy that results in a great invasive potential. It seems that this invasive plant could likely evolve into specialized ecotypes reaching zones with contrasting climatic conditions. We are still far from comprehending the full process of invasion and the associated putative evolutionary process, nonetheless assessing more species or performing integrative analysis (e.g., meta-analysis) we might find promising approaches to better understand the role of evolutionary processes in invasion.

\section{AUTHOR CONTRIBUTIONS}

MM-M, CT-D, IA-R, and CA designed the experiments. MM-M, $\mathrm{RH}, \mathrm{AL}$, and TF performed the experiments. MM-M, CT-D, IA-R, $\mathrm{RH}$, and TF analyzed the data. MM-M wrote the paper along with CT-D, IA-R, and CA. All authors reviewed the manuscript.

\section{ACKNOWLEDGMENTS}

We thank Bernardo Broitman for his valuable commentaries on the final version of the manuscript and grateful to Rodrigo Alvarez for his technical assistance in the experimental development. We also thank Robin Packeman for his insightful suggestions on an early version of the manuscript.

\section{SUPPLEMENTARY MATERIAL}

The Supplementary Material for this article can be found online at: https://www.frontiersin.org/articles/10.3389/fpls.2018.00208/ full\#supplementary-material

Brown, A. H. D., and Marshall, D. R. (1981). "Evolutionary changes accompanying colonization in plants," in Evolution Today, eds G. G. E. Scudder and J. L. Reveal (Pittsburgh: Carnegie-Mellon University Press), 351-363.

Cano, L., Escarre, J., Fleck, I., Blanco-Moreno, J. M., and Sans, F. X. (2008). Increased fitness and plasticity of an invasive species in its introduced range: a study using Senecio pterophorus. J. Ecol. 96, 468-476. doi: 10.1111/j.1365-2745. 2008.01363.x

Cavieres, L. A., Quiróz, C. L., and Molina-Montenegro, M. A. (2008). Facilitation of the non-native Taraxacum officinale by native nurse cushion species in the high Andes of central Chile: are there differences between nurses? Funct. Ecol. $22,148-156$.

Cavieres, L. A., Quiroz, C. L., Molina-Montenegro, M. A., Muñoz, A. A., and Pauchard, A. (2005). Nurse effect of the native cushion plant Azorella monantha on the invasive non-native Taraxacum officinale in the high-Andes of central Chile. Perspect. Plant Ecol. Evol. Syst. 7, 217-226. doi: 10.1016/j.ppees.2005. 09.002

Chun, Y. J., Collyer, M. L., Moloney, K. A., and Nason, J. D. (2007). Phenotypic plasticity of native vs. invasive purple Loosestrife: a two-state multivariate approach. Ecology 88, 1499-1512. doi: 10.1890/06-0856

Clements, J. C., Dracup, M., Buirchell, B. J., and Smith, C. G. (2002). Variation for seed coat and pod wall percentage and other traits in a germplasm collection and historical cultivars of lupinus. Aust. J. Agric. Res. 56, 75-83. doi: 10.1071/ AR03114 
Colautti, R. I., and Barrett, S. C. H. (2013). Rapid adaptation to climate facilitates range expansion of an invasive plant. Science 342, 364-366. doi: 10.1126/ science. 1242121

Colautti, R. I., and Lau, J. A. (2015). Contemporary evolution during invasion, evidence for differentiation, natural selection: and local adaptation. Mol. Ecol. 24, 1999-2017. doi: 10.1111/mec.13162

Cota-Sánchez, J. H., Remarchuk, K., and Ubayasena, K. (2006). Ready-to-use DNA extracted with a CTAB method adapted for herbarium specimens and mucilaginous plant tissue. Plant Mol. Biol. Rep. 24, 161-167. doi: 10.1007/ BF02914055

de Witte, L. C., Armbruster, G. F., Gielly, L., Taberlet, P., and Stöcklin, J. (2012). AFLP markers reveal high clonal diversity and extreme longevity in four key arctic-alpine species. Mol. Ecol. 21, 1081-1097. doi: 10.1111/j.1365-294X.2011. 05326.x

Dlugosh, K. M., and Parker, I. M. (2008). Founding events in species invasions, adaptive evolution, and the role of multiple introductions. Mol. Ecol. 17, 431-449. doi: 10.1111/j.1365-294X.2007.03538.x

Douhovnikoff, V., Cheng, A. M., and Dodd, R. S. (2004). Incidence, size and spatial structure of clones in second-growth stands of coast redwood, Sequoia sempervirens (Cupressaceae). Am. J. Bot. 91, 1140-1146. doi: 10.3732/ajb.91.7. 1140

Douhovnikoff, V., and Dodd, R. S. (2003). Intra-clonal variation and a similarity threshold for identification of clones: application to Salix exigua using AFLP molecular markers. Theor. Appl. Genet. 106, 1307-1315. doi: 10.1007/s00122003-1200-9

Doyle, J., and Doyle, J. L. (1987). Genomic plant DNA preparation from fresh tissue-CTAB method. Phytochem. Bull. 19, 11-15.

Dray, S., Dufour, A. B., and Chessel, D. (2007). The ade4 package-II: two-table and K-table methods. $R$ News 7, 47-52.

Excoffier, L., Smouse, P. E., and Quattro, J. M. (1992). Analysis of molecular variance inferred from metric distances among DNA haplotypes: application to human mitochondrial DNA restriction data. Genetics 131, 479-491.

Falconer, D. S. (1981). An Introduction to Quantitative Genetics. Harlow: Longman Press.

Frankham, R., Briscoe, D. A., and Ballou, J. D. (2002). Introduction to Conservation Genetics. Cambridge: Cambridge University Press. doi: 10.1017/ CBO9780511808999

Franks, S. J., and Weis, A. E. (2008). A change in climate causes rapid evolution of multiple life-history traits and their interactions in an annual plant. J. Evol. Biol. 21, 1321-1334. doi: 10.1111/j.1420-9101.2008.01566.x

García-Ramos, G., and Rodríguez, D. (2002). Evolutionary speed of species invasions. Evolution 56, 661-667. doi: 10.1554/0014-3820(2002)056[0661: ESOSI]2.0.CO;2

Geng, Y. P., Pan, X. Y., Xu, C. Y., Zhang, W. J., Li, B., Chen, J. K., et al. (2007). Phenotypic plasticity rather than locally adapted ecotypes allow the invasive alligator weed to colonize a wide range of habitats. Biol. Invasions 9, 245-256. doi: 10.1007/s10530-006-9029-1

Godoy, O., Valladares, F., and Castro-Díez, P. (2011). Multispecies comparison reveals that invasive and native plants differ in their traits but not in their plasticity. Funct. Ecol. 25, 1248-1253. doi: 10.1111/j.1365-2435.2011. 01886.x

Gomez, A., and Carvalho, G. R. (2000). Sex, parthenogenesis and genetic structure of rotifers: microsatellite analysis of contemporary and resting egg bank populations. Mol. Ecol. 9, 203-214. doi: 10.1046/j.1365-294x.2000. 00849.x

Gómez-González, S., Torres-Díaz, C., Bustos-Schindler, C., and Gianoli, E. (2011). Anthropogenic fire drives the evolution of seed traits. Proc. Natl. Acad. Sci. U.S.A. 108, 18743-18747. doi: 10.1073/pnas.1108863108

Gorim, L., and Asch, F. (2012). Effects of composition and share of seed coatings on the mobilization efficiency of cereal seeds during germination. J. Agron. Crop Sci. 198, 81-91. doi: 10.1111/j.1439-037X.2011.00490.x

Gutterman, Y. (1994). Strategies of seed dispersal and germination in plants inhabiting deserts. Bot. Rev. 60, 373-425. doi: 10.1007/BF02857924

Haig, H., and Westoby, M. (1990). "Inclusive fitness, seed resources, and maternal care," in Plant Reproductive Ecology, Patterns and Strategies, eds L. Lovett and J. Lovett (New York, NY: Oxford University Press), 60-79.

Holm, L., Doll, L., Holm, E., Pacheco, J., and Herberger, J. (1997). World Weeds, Natural Histories and Distributions. New York, NY: John Wiley and Sons.
Honek, A., Martinkova, Z., and Saska, P. (2011). Effect of size, taxonomic affiliation and geographic origin of dandelion (Taraxacum agg.) seeds on predation by ground beetles (Carabidae. Coleoptera). Basic Appl. Ecol. 12, 89-96. doi: 10. 1016/j.baae.2010.11.003

Hulme, P. E., and Barrett, S. C. H. (2013). Integrating trait- and niche-based approaches to assess contemporary evolution in alien plant species. J. Ecol. 101, 68-77. doi: 10.1111/1365-2745.12009

IPCC (2013). Intergovernmental Panel on Climate Change. New York, NY: Cambridge University press.

Jenniskens, M. J. P. J. (1984). Self-compatibility in diploid plants of Taraxacum section Taraxacum. Acta Bot. Neerl. 33, 71-80. doi: 10.1111/j.1438-8677.1984. tb01773.x

Jombart, T. (2008). adegenet, a R-package for the multivariate analysis of genetic markers. Bioinformatics 24, 1403-1405. doi: 10.1093/bioinformatics/ btn 129

Jombart, T., Devillard, S., and Balloux, F. (2010). Discriminant analysis of principal components, a new method for the analysis of genetically structured populations. BMC Genet. 11:94. doi: 10.1186/1471-2156-11-94

Kooyers, N. J., Greenlee, A. J., Colicchio, J. M., Oh, M., and Blackman, B. K. (2015). Replicate altitudinal clines reveal that evolutionary flexibility underlies adaptation to drought stress in annual Mimulus guttatus. New Phytol. 206, 152-165. doi: 10.1111/nph.13153

Kück, P., Greve, C., Misof, B., and Gimnich, F. (2012). Automated masking of AFLP markers improves reliability of phylogenetic analyses. PLoS One 7:e49119. doi: 10.1371/journal.pone.0049119

Lasso, E. (2008). The importance of setting the right genetic distance threshold for identification of clones using amplified fragment length polymorphism: a case study with five species in the tropical plant genus Piper. Mol. Ecol. Resour. 8, 74-82. doi: 10.1111/j.1471-8286.2007.01910.x

Lavergne, S., and Molofsky, J. (2007). Increased genetic variation and evolutionary potential drive the success of an invasive grass. Proc. Natl. Acad. Sci. U.S.A. 104, 3883-3888. doi: 10.1073/pnas.0607324104

Lee, C. E. (2002). Evolutionary genetics of invasive species. Trends Ecol. Evol. 17, 386-391. doi: 10.1016/S0169-5347(02)02554-5

Leger, E. A., and Rice, K. J. (2007). Assessing the speed and predictability of local adaptation in invasive California poppies (Eschscholzia californica). J. Evol. Biol. 20, 1090-1103. doi: 10.1111/j.1420-9101.2006.01292.x

Majesky, L., Vasut, R. J., Kitner, M., and Travnicek, B. (2012). The Pattern of genetic variability in apomictic clones of Taraxacum officinale indicates the alternation of asexual and sexual histories of apomicts. PLoS One 7:e41868. doi: 10.1371 /journal.pone.0041868

Mantel, N. (1967). The detection of disease clustering and a generalized regression approach. Cancer Res. 27, 209-220.

Maron, J. L., Vilà, M., Bommarco, R., Elmendorf, S., and Beardsley, P. (2004). Rapid evolution of an invasive plant. Ecol. Monogr. 74, 261-280. doi: 10.1890/03-4027

Matthei, O. J. (1995). Manual de las Malezas Que Crecen en Chile. Santiago de Chile: Alfabeta.

Mayr, E. (1965). “The nature of colonization in birds," in The Genetics of Colonizing Species, eds H. G. Baker and G. L. Stebbins (New York, NY: Academic Press), 29-47.

Meirmans, P. G., and Van Tienderen, P. H. (2004). GENOTYPE and GENODIVE: two programs for the analysis of genetic diversity of asexual organisms. Mol. Ecol. Resour. 4, 792-794. doi: 10.1111/j.1471-8286.2004. 00770.x

Mera, M., Jerez, R., Miranda, H., and Rouant, J. L. (2004). Seed coat specific weight in Lupinus angustifolius: influence of genotype and environment and relationship with seed coat proportion. Aust. J. Agric. Res. 55, 1189-1195. doi: 10.1071/AR04095

Meyer, S. E., and Allen, P. S. (1999). Ecological genetics of seed germination regulation in Bromus tectorum L. I. Phenotypic variance among and within populations. Oecologia 120, 27-34. doi: 10.1007/s004420050829

Moles, A. T., Ackerly, D. D., Webb, C. O., Tweddle, J. C., Dickie, J. B., Pitman, A. J., et al. (2005). Factors that shape seed mass evolution. Proc. Natl. Acad. Sci. U.S.A. 102, 10540-10544. doi: 10.1073/pnas.0501473102

Molina-Montenegro, M. A., Atala, C., and Gianoli, E. (2010). Phenotypic plasticity and performance of Taraxacum officinale (dandelion) in habitats of contrasting environmental heterogeneity. Biol. Invasions 12, 2277-2284. doi: 10.1007/ s10530-009-9638-6 
Molina-Montenegro, M. A., and Cavieres, L. A. (2010). Variación altitudinal de los atributos morfo-fisiológicos en dos especies de plantas alto-andinas y sus implicancias contra la fotoinhibición. Gayana Bot. 67, 1-11. doi: 10.4067/ S0717-66432010000100001

Molina-Montenegro, M. A., Cleland, E. E., Watts, S. M., and Broitman, B. R. (2012a). Can a breakdown in competition-colonization tradeoff help explain the success of exotic species in the California flora? OIKOS 121, 389-395. doi: 10.1111/j.1600-0706.2011.18943.x

Molina-Montenegro, M. A., del Pozo, A., and Gianoli, E. (2018). Ecophysiological basis of the Jack-and-Master strategy: Taraxacum officinale (dandelion) as an example of a successful invader. J. Plant Ecol. 11, 147-157.

Molina-Montenegro, M. A., and Naya, D. E. (2012). Latitudinal patterns in phenotypic plasticity and fitness-related traits, Assessing the climatic variability hypothesis $(\mathrm{CVH})$ with an invasive plant species. PLoS One 7:e47620. doi: 10.1371 /journal.pone.0047620

Molina-Montenegro, M. A., Palma-Rojas, C., Alcayaga-Olivares, Y., Oses, R., Corcuera, L. J., Cavieres, L. A., et al. (2013). Ecophysiological plasticity and local differentiation help explain the invasion success of Taraxacum officinale (dandelion) in South America. Ecography 36, 718-730. doi: 10.1111/j.16000587.2012.07758.x

Molina-Montenegro, M. A., Peñuelas, J., Munné-Bosh, S., and Sardans, J. (2012b). Higher plasticity in ecophysiological traits enhances the performance and invasion success of Taraxacum officinale (dandelion) in alpine environments. Biol. Invasions 14, 21-33. doi: 10.1007/s10530-0110055-2

Molina-Montenegro, M. A., Quiroz, C. L., Torres-Díaz, C., and Atala, C. (2011). Ecophysiological traits suggest local adaptation rather than plasticity in the invasive Taraxacum officinale (dandelion) from native and introduced habitat range. Plant Ecol. Divers. 4, 36-42.

Neuffer, B., and Hurka, H. (1999). Colonization history and introduction dynamics of Capsella bursa-pastoris (Brassicaceae) in North America: isozymes and quantitative traits. Mol. Ecol. 8, 1667-1681. doi: 10.1046/j.1365-294x.1999. 00752.x

Noodén, L. D., Blakley, K. A., and Grzybowski, J. M. (1985). Control of seed coat thickness and permeability in soybean. Plant Physiol. 79, 543-545. doi: $10.1104 /$ pp.79.2.543

Peakall, R., and Smouse, P. E. (2006). GENALEX 6: genetic analysis in Excel. Population genetic software for teaching and research. Mol. Ecol. Notes 6, 288-295. doi: 10.1111/j.1471-8286.2005.01155.x

Phillips, B. L., Brown, G. P., Webb, J. K., and Shine, R. (2006). Invasion and the evolution of speed in toads. Nature 439:803. doi: 10.1038/439803a

Prendeville, H. R., Barnard-Kubow, K., Dai, C., Barringer, B. C., and Galloway, L. F. (2013). Clinal variation for only some phenological traits across a species range. Oecologia 173, 421-430. doi: 10.1007/s00442-013-2630-y

Pysek, P., Manceur, M. A., Alba, C., McGregor, K. F., Pergl, J., Stajerová, K., et al. (2015). Naturalization of central European plants in North America: species traits, habitats, propagule pressure, residence time. Ecology 96, 762-774. doi: 10.1890/14-1005.1

Pysek, P., and Richardson, D. M. (2007). "Traits associated with invasiveness in alien plants: where do we stay?" in Biological Invasions, ed. M. M. Caldwell (Berlin: Springer), 97-125.

Quiroz, C. L., Choler, P., Baptist, F., Molina-Montenegro, M. A., GonzálezTeuber, M., and Cavieres, L. A. (2009). Alpine dandelions originated in the native and introduced range differ in their responses to environmental constraints. Ecol. Res. 24, 175-183. doi: 10.1007/s11284-008-0498-9

R Core Team (2015). R: A Language and Environment for Statistical Computing. Vienna: R Foundation for Statistical Computing. Available at: http://www.Rproject.org/

Rejmánek, M., Richardson, D. M., Higgins, S. I., Pitcairn, M. J., and Grotkopp, E. (2005). "Ecology of invasive plants, state of the art," in Invasive Alien Species a New Synthesis, eds H. A. Mooney, R. N. Mack, J. A. McNeely, L. E. Neville, P. J. Schei, and J. K. Waage (Washington DC: Island Press), 104-161.

Reznick, D. N., and Ghalambor, C. K. (2001). The population ecology of contemporary adaptations, what empirical studies reveal about the conditions that promote adaptive evolution. Genetica 112, 183-198. doi: 10.1023/A: 1013352109042
Rogers, W. E., and Siemann, E. (2004). Invasive ecotypes tolerate herbivory more effectively than native ecotypes of the chinese tallow tree Sapium sebiferum. J. Appl. Ecol. 41, 561-570. doi: 10.1111/j.0021-8901.2004. 00914.x

Rogstad, S. H., Keane, B., and Beresh, J. (2002). Genetic variation across VNTR loci in central North American Taraxacum surveyed at different spatial scales. Plant Ecol. 161, 111-121. doi: 10.1023/A:1020301011283

Santamaría, L., Figuerola, J., Pilon, J. J., Mjelde, M., Green, A. J., de Boer, T., et al. (2003). Plant performance across latitude, the role of plasticity and local adaptation in an aquatic plant. Ecology 84, 2454-2461. doi: 10.1890/02-0431

Sax, D. F., Stachowicz, J. J., Brown, J. H., Bruno, J. F., Dawson, M. N., Gaines, S. D., et al. (2007). Ecological and evolutionary insights from species invasions. Trends Ecol. Evol. 22, 465-471. doi: 10.1016/j.tree.2007.06.009

Schierenbeck, K. A., and Ellstrand, N. C. (2009). Hybridization and evolution of invasiveness in plants and other organisms. Biol. Invasions 11, 1093-1105. doi: 10.1007/s10530-008-9388-x

Sexton, J. P., McKay, J. K., and Sala, A. (2002). Plasticity and genetic diversity may allow salt cedar to invade cold climates in North America. Ecol. Appl. 12, 1652-1660. doi: 10.1890/1051-0761(2002)012[1652:PAGDMA]2.0.CO;2

Suarez, A. V., and Tsutsui, N. D. (2008). The evolutionary consequences of biological invasions. Mol. Ecol. 17, 351-360. doi: 10.1111/j.1365-294X.2007. 03456.x

Thorpe, A. S., Aschehoug, E. T., Atwater, D. Z., and Callaway, R. M. (2011). Interactions among plants and evolution. J. Ecol. 99, 729-740. doi: 10.1111/j. 1365-2745.2011.01802.x

Tweney, J., and Mogie, M. (1999). The relationship between achene weight, embryo weight and germination in Taraxacum apomicts. Annu. Bot. 83, 45-50. doi: 10.1006/anbo.1998.0790

Urbanski, J., Mogi, M., O’Donnell, D., De Cotiis, M., Toma, T., and Armbruster, P. (2012). Rapid adaptive evolution of photoperiodic response during invasion and range expansion across a climatic gradient. Am. Nat. 179, 490-500. doi: 10.1086/664709

Valladares, F., Matesanz, S., Guilhaumon, F., Araujo, M. B., Balaguer, L., BenitoGarzón, M., et al. (2014). The effects of phenotypic plasticity and local adaptation on forecasts of species range shifts under climate change. Ecol. Lett. 17, 1351-1364. doi: 10.1111/ele.12348

van der Hulst, R. G. M., Mes, T. H. M., Den Nijs, J. C. M., and Bachmann, K. (2000). Amplified fragment length polymorphism (AFLP) markers reveal that population structure of triploid dandelions (Taraxacum officinale) exhibits both clonality and recombination. Mol. Ecol. 9, 1-8. doi: 10.1046/j.1365-294x.2000. 00704.x

van Kleunen, M., Weber, E., and Fischer, M. (2010). A meta-analysis of trait differences between invasive and non-invasive plant species. Ecol. Lett. 13, 235-245. doi: 10.1111/j.1461-0248.2009.01418.x

Vellend, M., Drummond, E. B. M., and Tomimatsu, H. (2010). Effects of genotype identity and diversity on the invasiveness and invasibility of plant populations. Oecologia 162, 371-381. doi: 10.1007/s00442-009-1480-0

Vos, P., Hogers, R., Marjo, B., Reijans, M., Van de Lee, T., Hornes, M., et al. (1995). AFLP, A new technique for DNA fingerprinting. Nucleic Acids Res. 23, 4407-4414. doi: 10.1093/nar/23.21.4407

Whitney, K. D., and Gabler, C. A. (2008). Rapid evolution in introduced species, 'invasive traits' and recipient communities: challenges for predicting invasive potential. Divers. Distrib. 14, 569-580. doi: 10.1111/j.1472-4642.2008.00473.x Zar, J. H. (1996). Biostatistical Analysis. London: Prentice-Hall.

Conflict of Interest Statement: The authors declare that the research was conducted in the absence of any commercial or financial relationships that could be construed as a potential conflict of interest.

Copyright (C) 2018 Molina-Montenegro, Acuña-Rodríguez, Flores, Hereme, Lafon, Atala and Torres-Díaz. This is an open-access article distributed under the terms of the Creative Commons Attribution License (CC BY). The use, distribution or reproduction in other forums is permitted, provided the original author(s) and the copyright owner are credited and that the original publication in this journal is cited, in accordance with accepted academic practice. No use, distribution or reproduction is permitted which does not comply with these terms. 